Journal of Korean Powder Metallurgy Institute

Vol. 18, No. 3, 2011

DOI: $10.4150 /$ KPMI.2011.18.3.250

\title{
Oxygen-Response Ability of Hydrogen-Reduced Nanocrystalline Cerium Oxide
}

\author{
Dong-Won Lee* \\ Powder Technology Research Group, Korea Institute of Materials Science (KIMS), \\ Changwon, Kyungnam 641-830, Korea \\ (Received March 17, 2011; Revised April 22, 2011; Accepted May 4, 2011)
}

\begin{abstract}
The potential application of ultrafine cerium oxide (ceria, $\mathrm{CeO}_{2}$ ) as an oxygen gas sensor has been investigated. Ceria was synthesized by a thermochemical process: first, a precursor powder was prepared by spray drying cerium-nitrate solution. Heat treatment in air was then performed to evaporate the volatile components in the precursor, thereby forming nanostructured $\mathrm{CeO}_{2}$ having a size of approximately $20 \mathrm{~nm}$ and specific surface area of $100 \mathrm{~m}^{2} / \mathrm{g}$. After sintering with loosely compacted samples, hydrogen-reduction heat treatment was performed at $773 \mathrm{~K}$ to increase the degree of non-stoichiometry, $\mathrm{x}$, in $\mathrm{CeO}_{2-\mathrm{x}}$. In this manner, the electrical conductivity and oxygen-response ability could be enhanced by increasing the number of oxygen vacancies. After the hydrogen reduction at $773 \mathrm{~K}, \mathrm{CeO}_{1.5}$ was obtained with nearly the same initial crystalline size and surface. The response time $t_{90}$ measured at room temperature was extremely short at $4 \mathrm{~s}$ as compared to $14 \mathrm{~s}$ for normally sintered $\mathrm{CeO}_{2}$. We believe that this hydrogen-reduced ceria can perform capably as a high-performance oxygen sensor with good response abilities even at room temperature.
\end{abstract}

Keywords: Cerium oxide, Oxygen gas sensor, Nanoparticles, Thermochemical process

\section{Introduction}

Oxygen gas sensors have been actively developed for a wide variety of applications such as in medical incubators for infants and in various oxygen providers; exhaust gas sensors have also been employed in gasoline-powered automobiles [1]. Currently, the most widely used oxygen gas sensors are oxygen-ion-conductor cells made of yttrium-stabilized zirconia (YSZ); they are used for measuring the oxygen concentration in exhaust gases [2]. In this sensor, a cell-type structure is employed to detect the differences in the oxygen concentration between a reference electrode and a sensing electrode. This not only makes the device structure complicated, but it is also difficult to reduce the sensor size; moreover, the working temperature is also relatively high $(\sim 1123 \mathrm{~K})$ [3].

On the other hand, a resistive type of oxygen sen- sor made of single-phase oxides has exhibited some promising features such as high oxygen-sensing capabilities, short response times and accomplished by easy particle refinement to nanometer scale, relatively low working temperatures and easy miniaturization of sensor devices due to its simple sensing mechanism [3, 4]. Among the materials for resistive oxygen sensors, a good candidate is cerium oxide (ceria, $\mathrm{CeO}_{2}$ ) [5, 6]. The high oxygen sensibility of ceria, with its wide range of oxygen non-stoichiometry $\left(\mathrm{CeO}_{1.5 \sim 2.0}\right)$, originates from its unique crystal structure in which significant amounts of oxygen vacancies provide good electrical mobility [7].

Furthermore, particle refinement causes many defects in surfaces, which leads to an increase of the $\times$ value in $\mathrm{CeO}_{2-\mathrm{x}}$; this in turn increases electrical conductivity. Hence, the particle refinement is very important

*Corresponding Author : [Tel : +82-55-280-3524; E-mail : ldw1623@kims.re.kr] 
to increase electrical conductivity. In our previous work, nanostructured ceria powders having a size of $20 \mathrm{~nm}$ and specific surface area of $100 \mathrm{~m}^{2} / \mathrm{g}$ were synthesized by thermochemical processes and the oxygen response time $\left(t_{90}\right)$ was studied [8]. Moreover, it was also reported that micron-sized ceria particles showed rapid increase in electrical conductivity with the degree of non-stoichiometry after hydrogen-reduction heat treatment [9]. In this study, we have attempted to understand the effects of hydrogen-reduction heat treatment on $t_{90}$ and the powder properties of nano-sized ceria produced by thermochemical processes.

\section{Experimental}

The thermochemical processes consisted of two simple steps: (1) the preparation of the precursor by spray drying of cerium-nitrate solution and (2) the formation of ceria during heat treatment of the precursor in air. Subsequently, the spray-dried precursor was heat treated at $673 \mathrm{~K}$ for $2 \mathrm{~h}$ in air to remove any volatile moisture content and $\mathrm{NO}_{3}$ components. Simultaneously, the cerium component was oxidized to form nanostructured cerium oxide. The produced powders were compacted loosely at $1.5 \mathrm{~Pa} / \mathrm{cm}^{2}$ and sintered at $1273 \mathrm{~K}$ for $1 \mathrm{~h}$ in air. The dimensions of the plate-type sintered specimens were approximately $0.5 \mathrm{~mm} \times 5 \mathrm{~mm} \times 12 \mathrm{~mm}$. The sintered samples were then heat-treated from $473 \mathrm{~K}$ to $1273 \mathrm{~K}$ in hydrogen at a flow rate of $1 \mathrm{l} / \mathrm{min}$.

All the powders and sintered specimens were examined by using a scanning electron microscope (HITACHI S4200) and $\mathrm{Cu} K \alpha$ X-ray diffraction (RIKAKU R2000). The electrical resistance was measured using a multimeter (KEITHLEY 2000); here, four-probe-type platinum electrodes $(5 \mathrm{~mm} \times 5$ $\mathrm{mm}$ ) were contacted on both sides of a sintered plate. Finally, the oxygen response times, $t_{90}$ were obtained from the resistance profiles that varied with sudden changes in the oxygen partial pressure from 0.2 to 0 at room temperature.

\section{Results and Discussion}

During the spray drying, helically generated droplets were dried inside the chamber, leading to the formation of amorphous particles comprising $\mathrm{Ce}-\mathrm{O}-$ $\mathrm{NO}_{3}$ components and small amounts of moisture. The particles were fully transformed into the cerium oxide phase after the removal of volatile components by heat treatment in air at $673 \mathrm{~K}$. The formation of the amorphous phase by spray drying and the nanosized oxide particles by the de-binding heat treatment has been studied previously $[9,10]$.

Fig. 1 shows the morphology of the ceria particles after the de-binding treatment. The ceria particles were extremely fine and nearly spherical with a diameter of approximately $15 \mathrm{~nm}$. Further, they were loosely agglomerated with a specific surface area of $110 \mathrm{~m}^{2} / \mathrm{g}$. Moreover, the phase was revealed to be pure cerium oxide (JCPDS file No. 34-0394) [8].

In the next step, to prepare the sample for electrical resistivity measurements, the de-binding powders were loosely compressed and sintered at $1273 \mathrm{~K}$ for $2 \mathrm{~h}$; its SEM microstructure is shown in Fig. 2. The low-magnification figure (Fig. 2a) shows a flat surface well formed by die compaction, while the size of internal particles still remained approximately $40 \mathrm{~nm}$ with a good porous structure (Fig. 2b).

It is interesting that gradual weight loss occurred

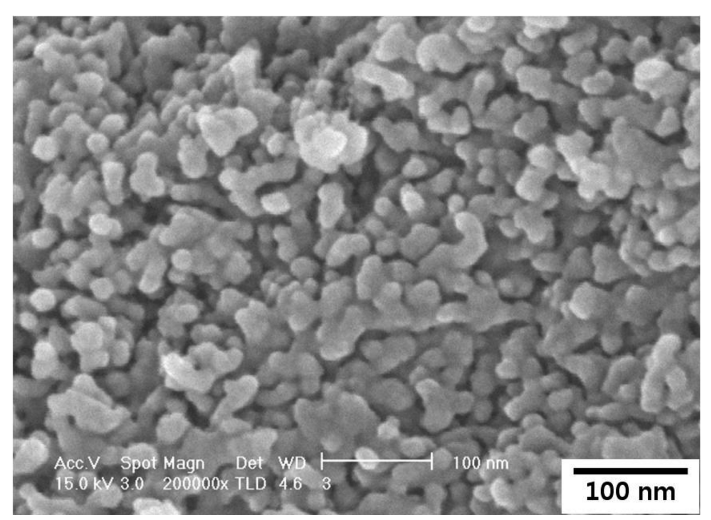

Fig. 1. SEM microstructure of cerium oxide particles obtained after debinding heat treatment in air at $673 \mathrm{~K}$ for $2 \mathrm{~h}$. 

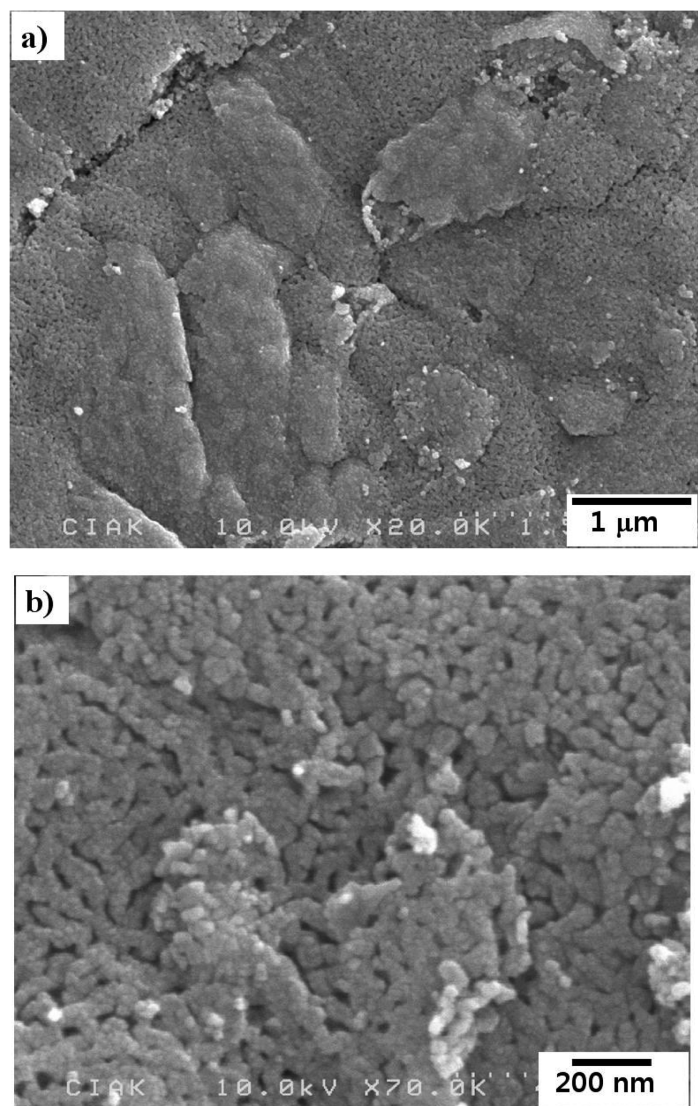

Fig. 2. SEM microstructures at (a) low and (b) high magnifications for ceria sample sintered at $1273 \mathrm{~K}$ for $1 \mathrm{~h}$.

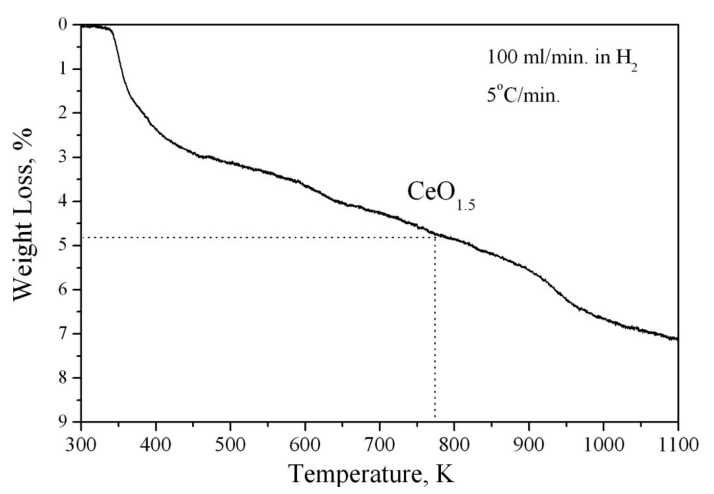

Fig. 3. Thermogravimetric (TG) profile during heating of sintered sample at heating rate of $5^{\circ} \mathrm{C} / \mathrm{min}$ in hydrogen atmosphere.

during the continuous heating at $5^{\circ} \mathrm{C} / \mathrm{min}$ in hydrogen atmosphere as result of the reduction effect of the reaction $\mathrm{CeO}_{2}+\mathrm{xH}_{2} \rightarrow \mathrm{CeO}_{2-\mathrm{x}}+\mathrm{xH}_{2} \mathrm{O}$. In the
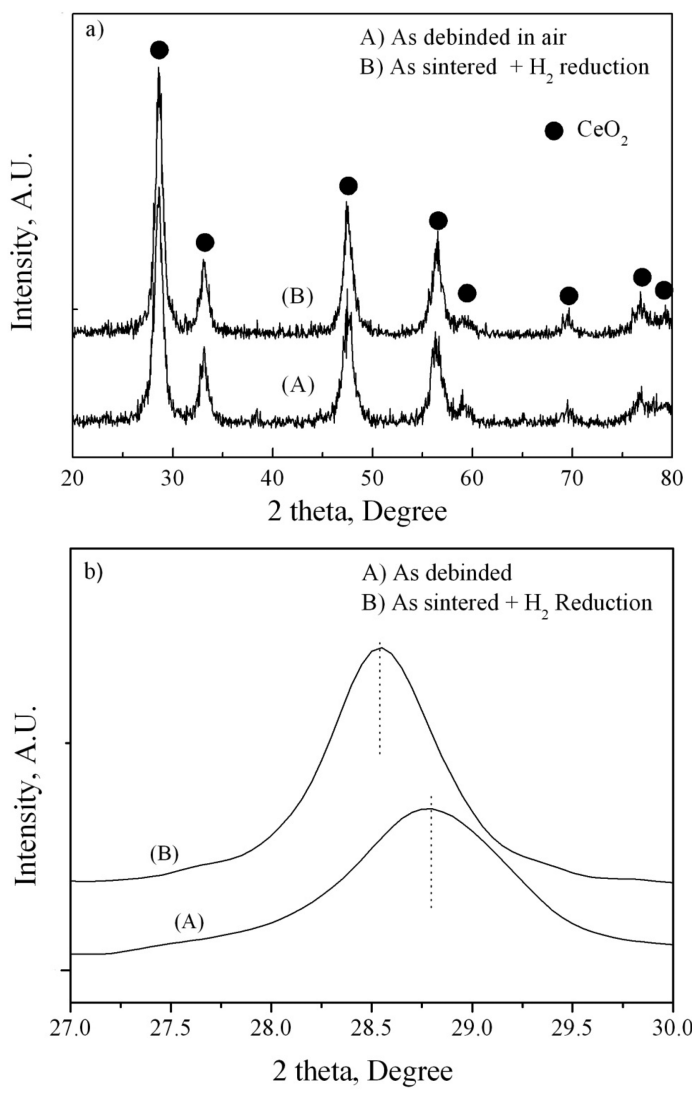

Fig. 4. X-ray diffraction patterns measured in samples sintered and further $\mathrm{H}_{2}$-reduced at $773 \mathrm{~K}$ for $1 \mathrm{~h}$ (a) normal and (b) magnified patterns reflected at (111) crystal plane.

thermogravimetric profile shown in Fig. 3, it was found that the stoichiometry decreased to $\mathrm{CeO}_{1.5}$ by the reduction effect at $773 \mathrm{~K}$, and it further decreases at elevated temperatures.

The X-ray diffraction patterns in Fig. 4 show that at $873 \mathrm{~K}$, the samples were sintered and further hydrogen-reduced. Both the normal and magnified images shown the ceria phase; moreover, the magnified profile showed left-shift for the reflection at the (111) plane by hydrogen heat treatment. Such peak shifting obviously resulted from an increase in the lattice parameter caused by the formation of oxygen deficiencies [11].

Sample characterizations were obtained after hydrogen-reduction heat treatment at various temperatures (Fig. 5). Fig. 5 indicates that the particle coarsening 


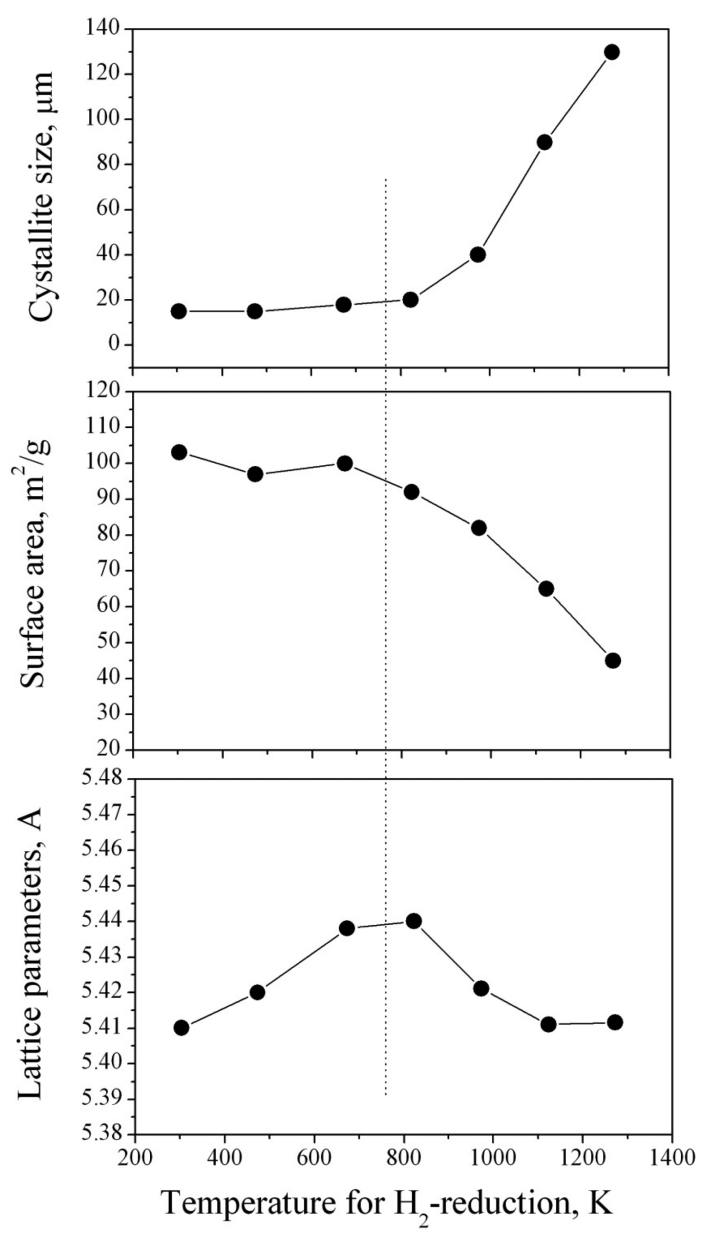

Fig. 5. Changes in crystal sizes, surface areas, and lattice parameters of ceria samples obtained after hydrogenreduction heat treatments at various temperatures for $1 \mathrm{~h}$.

was inhibited until $773 \mathrm{~K}$, and the specific area was maintained at around $100 \mathrm{~m}^{2} / \mathrm{g}$. It can be theorized that the hydrogen reduction occurs particularly on the particle surface. The lattice parameter reached maximum value around $773 \mathrm{~K}$ but decreased with higher temperatures due to the core-bulk effect of particle coarsening.

SEM microstructures of the ceria samples that were hydrogen-reduced for $1 \mathrm{~h}$ at $573 \mathrm{~K}, 973 \mathrm{~K}$, and $1273 \mathrm{~K}$ are shown in Fig. 6. Slight coarsening of the particles occurred at $973 \mathrm{~K}$, while at the elevated temperature of $1273 \mathrm{~K}$, the particle growth was considerable, which is probably a result of crystal insta-
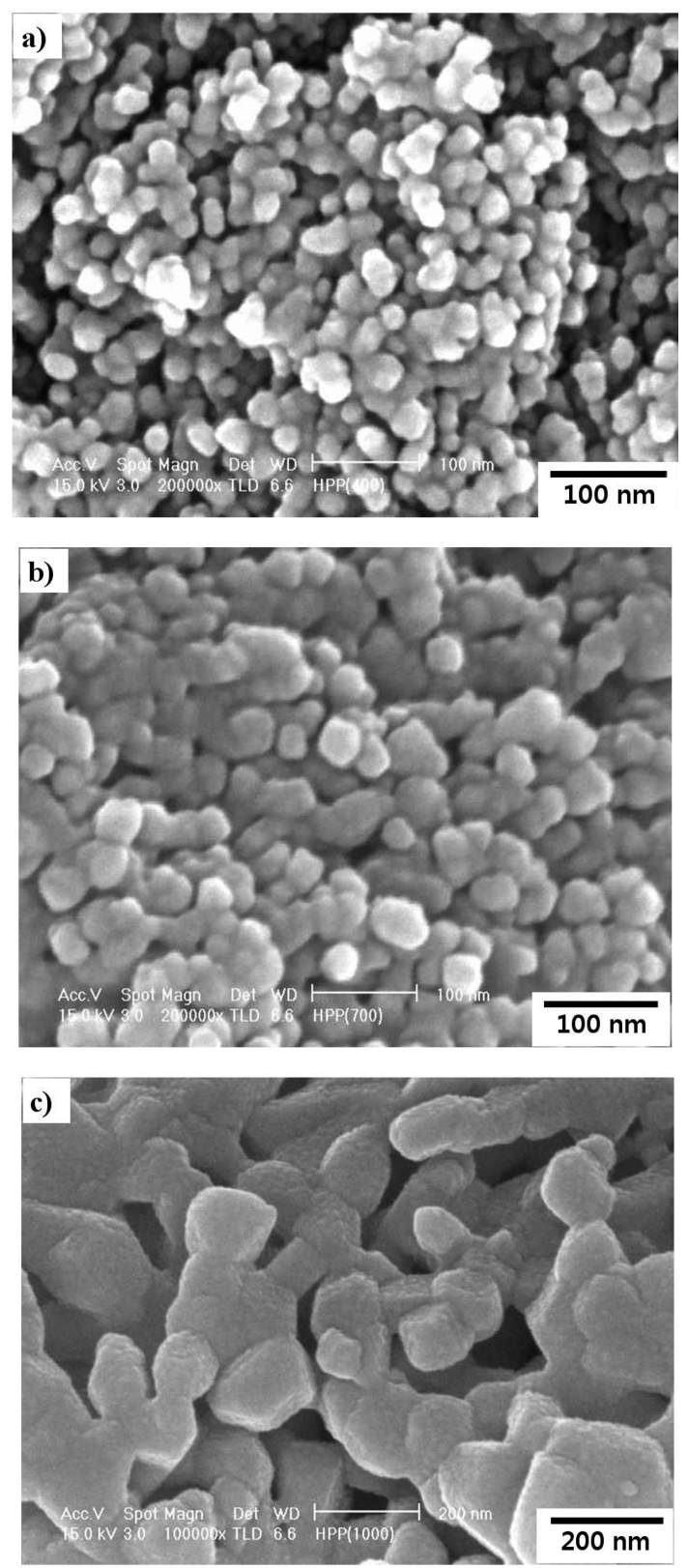

Fig. 6. SEM microstructures of ceria samples hydrogenreduced for $1 \mathrm{~h}$ at (a) $673 \mathrm{~K}$, (b) $973 \mathrm{~K}$, and (c) $1273 \mathrm{~K}$ after sintering.

bility due to the oxygen deficiencies. Finally, from Fig. 3, Fig. 4 and Fig. 5, it can be decided that the optimum temperature for $\mathrm{H}_{2}$-reduction heat treatment was $773 \mathrm{~K}$; the maximum values of the lattice parameter and surface areas were obtained at this 
temperature.

It is important to conduct detailed measurements of the lattice parameters from the results of X-ray diffraction patterns obtained in the ceria samples before and after the hydrogen heat treatment at $773 \mathrm{~K}$. The extrapolation technique was used to define it [12].

$a_{i}$ is each lattice parameter measured by each peak reflected at each $\left(h_{i}, k_{\dot{i}}, l_{i}\right)$ plane; it is given by the following equation:

$$
a_{i}=\left(h_{i}^{2}+k_{i}^{2}+l_{i}^{2}\right)^{1 / 2} \times \lambda / 2 \sin \theta
$$

Further, $f\left(\theta_{i}\right)$ is a function obtained using the following equation, wherein the theta-value corresponds to the $\left(h_{i}, k_{i}, l_{i}\right)$ peak.

$$
f\left(\theta_{i}\right)=\cos ^{2} \theta_{i} / \sin \theta_{i}+\cos ^{2} \theta_{i} / \theta_{i}
$$

In other words, the real lattice parameter can be defined as $f\left(\theta_{i}\right)$ approaches zero. Fig. 7 shows the results of applying the above concept; the lattice parameter measured in the samples sintered and hydrogen treated were $5.416 \AA$ and $5.442 \AA$, respectively. This clearly demonstrates the considerable increase in the lattice parameter by hydrogen reduction [11]. The slight difference in the lattice parameter values between the sintered sample and the JCPDS standard can be explained by the different particle sizes or sample structures of the used ceria materials.

Finally, the oxygen response-abilities of the sin-

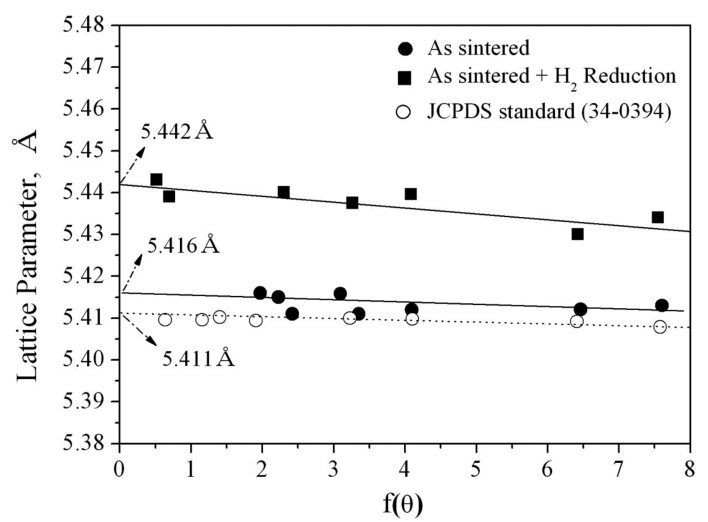

Fig. 7. Determination of lattice parameters of sintered and hydrogen-reduced ceria. tered and post $\mathrm{H}_{2}$-reduced samples are compared. Ceria is known to a n-type semiconductor, and its electrical conductivity is dominated by the mobility of the electrons trapped by cerium and oxygen vacancies [7]. From the formation of one oxygen vacancy, 2 electrons can contribute to the conductivity as follows:

$$
2 \mathrm{Ce}_{\mathrm{Ce}}^{\mathrm{x}}+\mathrm{O}_{\mathrm{o}}^{\mathrm{x}}=2 \mathrm{Ce}_{\mathrm{Ce}}+\mathrm{V}^{* *}{ }_{\mathrm{o}}+1 / 2 \mathrm{O}_{2}
$$

Here $\mathrm{Ce}^{\mathrm{x}}{ }_{\mathrm{Ce}}$ and $\mathrm{O}_{\mathrm{o}}^{\mathrm{x}}$ are regular lattice ions whereas $\mathrm{Ce}{ }_{\mathrm{Ce}}$ and $\mathrm{V}^{* *}{ }_{\mathrm{o}}$ are charged defects; $\mathrm{Ce}{ }_{\mathrm{Ce}}$ represents the electron trapped by $\mathrm{Ce}^{\mathrm{x}}{ }_{\mathrm{Ce}}$ while $\mathrm{V}^{* *}{ }_{\mathrm{o}}$ represents the doubly ionized oxygen vacancies. Accordingly, the high density of mobile electrons, $\mathrm{Ce}_{\mathrm{Ce}}^{\mathrm{x}}$ may help to increase the response ability against any sudden changes in the oxygen partial pressure. It has also been considered that the electron density as well as the vacancy density is higher in the $\mathrm{H}_{2}$-reduced sample due to the oxygen reduction effect. The normalized resistance profiles measured at room temperature with the sudden changes from air to argon atmosphere - are compared in Fig. 8. Actually, the resistance signal could not be detected at room temperature in normal micron-sized ceria sample by our multi-meter because it was nearly non-conducting material.

The response time $t_{90}$ was obtained after normalizing the actual resistance profiles. It is considerably

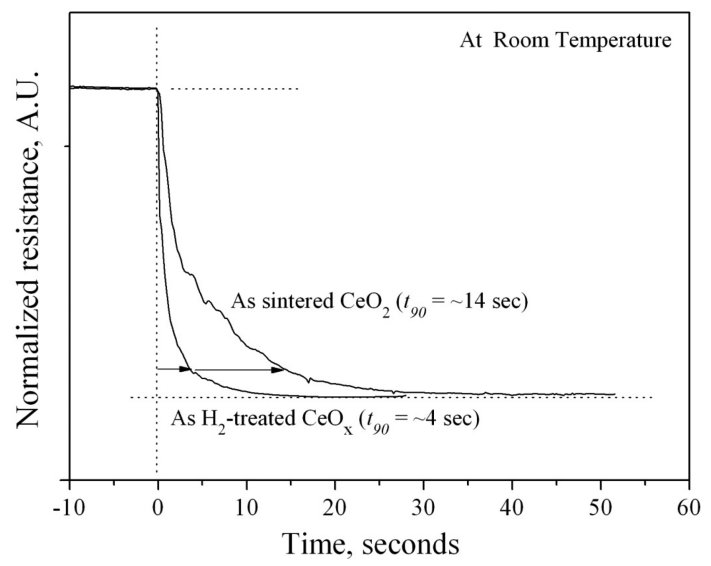

Fig. 8. Comparison of the response times $t_{90}$ of sintered and hydrogen-reduced ceria. 
shorter (4s) than that in the sintered sample (14 s). In our previous work, $t_{90}$ in sintered nano-ceria was $3 \sim 5 \mathrm{~s}$ at $973 \mathrm{~K}$ [8]. Moreover, it has been reported that $t_{90}$ is $8 \sim 35 \mathrm{~s}$ at $1080 \sim 1275 \mathrm{~K}$ in $1 \mathrm{~mm}$ ceria [13], $8 \mathrm{~s}$ at $1080 \mathrm{~K}$ in $200 \mathrm{~nm}$ ceria [14], and $10 \sim 11 \mathrm{~s}$ at $888 \sim 936 \mathrm{~K}$ in $100 \mathrm{~nm}$ ceria [15]. Therefore, it must be emphasized that $t_{90}$ obtained in this study is very short even at room temperature. Therefore, it is believed that the developed $\mathrm{H}_{2}$-reduced ceria can perform as a high-performance $\mathrm{O}_{2}$-sensor with good response abilities even at room temperature.

\section{Conclusions}

Nanostructured ceria particles having a size of approximately $15 \mathrm{~nm}$ were successfully synthesized by thermochemical processes. Precursor powder was prepared by spray drying cerium-nitrate solution and then heat-treating at $673 \mathrm{~K}$ in air to evaporate volatile components, thereby forming nanostructured ceria. The average grain size of sintered ceria at $1273 \mathrm{~K}$ was approximately $40 \mathrm{~nm}$. By hydrogen reduction of the sintered sample, the lattice parameter and nonstoichiometric degree were increased. The response time $t_{90}$ of the hydrogen-reduced specimen was $4 \mathrm{~s}$, which is considerably shorter than that of normal sintered nano-ceria, $14 \mathrm{~s}$. This $\mathrm{H}_{2}$-reduced ceria can capably perform as a high-performance $\mathrm{O}_{2}$-sensor even at room temperature. We are now investigating sensor reliability as well as device miniaturization techniques to maximize the resistance signal.

\section{References}

[1] M. Ogita, K. Higo, Y. Nakanishi and Y. Hatanaka: Appl. Surf. Sci., 175 (2001) 721.

[2] D. Pribat and G. Velasco: Sens. Actuat., B13 (1998) 173.

[3] N. Izu, W. S. Shin and N. Murayama: Sens. Actuat., B94 (2003) 222.

[4] N. Izu, W. S. Shin and N. Murayama: Sens. Actuat., B100 (2004) 411.

[5] U. Lamp, J. Gerblinger and H. Meixner: Sens. Actuat., B7 (1992) 787.

[6] J. Gerblinger, W. lohwasser, U. Lampe and H. Meixner: Sens. Actuat., B26-27 (1995) 93.

[7] H. J. Beie and A. Gnorich: Sens. Actuat., B4 (1991) 393.

[8] D. W. Lee, J. H. Yu, T. S. Lim and T. S. Jang: Materials Science Forum, 534-536 (2007) 61.

[9] H. A. Al-Madfaa and M. M. Khader: Mater. Chem. and Phys., 86 (2004) 180.

[10] D. W. Lee and B. K. Kim: Materials Letters., 58 (2004) 378.

[11] S. Tsunekawa, R. Sivamohan, S. Ito, A. Kasuya and T. Fukuda: Nanostruct. Mater., 11 (1999) 141.

[12] D. W. Kim and B. K. Kim: Scripta Materialia, 48 (2003) 1513.

[13] N. Izu, W. Shin and N. Murayama: Sens. Actuat., B87 (2002) 99.

[14] N. Izu, W. Shin, N. Murayama and S. Kanzaki: Sens. Actuat., B87 (2002) 95.

[15] N. Izu, W. Shin, I. Matsubara and N. Murayama: Sens. Actuat., B94 (2003) 222. 